Sarikaya et al. Hawai'ian Drosophila

\title{
1 Reproductive capacity evolves in response to ecology through common developmental
} mechanisms in Hawai'ian Drosophila

4 Didem P. Sarikaya ${ }^{1,2^{*}}$, Samuel H. Church ${ }^{1}$, Laura P. Lagomarsino ${ }^{3}$, Karl N. Magnacca ${ }^{4}$, Steven 5 Montgomery $^{4}$, Donald K. Price ${ }^{5,6}$, Kenneth Y. Kaneshiro ${ }^{7}$ and Cassandra G. Extavour ${ }^{1,8^{*}}$

1. Department of Organismic and Evolutionary Biology, Harvard University, Cambridge MA 02138

2. Current address: Evolution and Ecology Department, University of California Davis, Davis CA 95616

D.P.Sarikaya didemps@gmail.com, Evolution and Ecology Department, 
Sarikaya et al. Hawai'ian Drosophila

\section{Abstract}

31 Lifetime reproductive capacity, or the total number of offspring that an individual can give rise

32 to in its lifetime, is a fitness component critical to the evolutionary process. In insects, female

33 reproductive capacity is largely determined by the number of ovarioles, the egg-producing

34 subunits of the ovary. Recent work has provided insights into the genetic and environmental

35 control of ovariole number in Drosophila melanogaster. However, whether regulatory

36 mechanisms discovered under laboratory conditions also explain evolutionary variation in

37 natural populations is an outstanding question. Here we report, for the first time, insights into the

38 mechanisms regulating ovariole number and its evolution among Hawai'ian Drosophila, a large

39 adaptive radiation of fruit flies in which the highest and lowest ovariole numbers of the genus

40 have evolved within 25 million years. Using phylogenetic comparative methods, we show that

41 ovariole number variation among Hawai'ian Drosophila is best explained by adaptation to

42 specific oviposition substrates. Further, we show that evolution of oviposition on ephemeral egg-

43 laying substrates is linked to changes the allometric relationship between body size and ovariole

44 number. Finally, we provide evidence that the developmental mechanism principally responsible

45 for controlling ovariole number in D. melanogaster also regulates ovariole number in natural

46 populations of Hawai'ian drosophilids. By integrating ecology, organismal growth, and cell

47 behavior during development to understand the evolution of ovariole number, this work connects

48 the ultimate and proximate mechanisms of evolutionary change in reproductive capacity.

50 Keywords: ovary, ovariole, terminal filament, adaptive radiation, allometry, constraint 
Sarikaya et al. Hawai'ian Drosophila

\section{Introduction}

Reproductive capacity is an important life history trait that directly influences fitness by

53 determining how many offspring an individual can leave behind. There is a wide range in

54 potential fecundity across species $(1,2)$, which is often interpreted as trade-offs with presumed

55 ecological and developmental constraints . Trade-offs have been invoked to explain patterns of

56 egg-laying in animals, where total fecundity can correlate negatively with egg mass, clutch size

57 or lifespan (3-10), and positively with body size (11-13). In addition to these hypothesized

58 physical or growth-related constraints, life history parameters including predation risk,

59 environmental variability, host specialization and levels of parental care have been proposed to

60 influence evolutionary change in fecundity $(1,14-17)$, suggesting that this trait could represent a

61 complex intersection between ecology and physiology. However, few studies have addressed

62 how female reproductive capacity evolves in response to ecology, and how these pressures

63 manifest as different phenotypes through changes in development.

64 In insects, female reproductive capacity is strongly influenced by the number of egg-

65 producing structures called ovarioles $(1,18-23)$. Ovariole number is species-specific and

66 genetically determined $(24,25)$. Most insects have limited intraspecific variation in ovariole

67 number, and the effect of ovariole number on fecundity has been observed by comparing mean

68 ovariole numbers within or between species. In many insects, including beetles, fruit flies, and

69 aphids, ovariole number is positively correlated with fecundity between and within species (1,

70 21-23). For example, Drosophila melanogaster strains with naturally occurring or genetically

71 manipulated higher ovariole numbers both show increased fecundity $(18,26)$. While

72 physiological traits like egg production rate may also play an important role in determining

73 reproductive capacity (27), these can be difficult to assess in laboratory settings where egg- 
Sarikaya et al. Hawai'ian Drosophila

74 laying conditions may not be suitable for some insects. In contrast, ovariole number has served

75 as a proxy for reproductive capacity for decades (18), as it is a quantitative trait that can be easily

76 measured from field and laboratory samples.

77 Ovariole number is established during larval and pupal stages (20), and can be affected

78 by environmental conditions during this phase of development, including nutrition and

79 temperature $(24,28,29)$. During larval development, a specific group of cells called terminal

80 filament cells (TFCs) form stacks called terminal filaments (TFs) that serve as the beginning

81 point of each ovariole (30-33). Developmental mechanisms of ovariole number evolution are

82 best characterized in species of the African melanogaster subgroup of Drosophila, where

83 average ovariole number ranges from 43 to 18 per female $(1,34)$, and ovariole number

84 differences result primarily from changes in TFC number $(29,35)$. Ovariole number is highly

85 polygenic and regulated by pleiotropic genes (25), thus offering an opportunity to study the

86 evolution of a complex quantitative trait in response to different environments.

87 Major shifts in ovariole number have been attributed to aspects of life history.

88 Ovoviviparity, where females oviposit first instar larvae, is often correlated with reduced

89 ovariole number (16), suggesting that increased parental investment is linked to reduced

90 fecundity as observed in other animals (17). The stability of the environment and the

91 predictability of egg-laying substrates may influence evolution of ovariole number, as more

92 stable environments or abundant substrates are correlated with higher ovariole number, and

93 species occupying unpredictable environments or scarce substrates tend to have lower ovariole

94 numbers $(15,36)$. In the well-studied Drosophila melanogaster subgroup, previous studies have

95 suggested that reproductive strategies and ovariole number evolve in response to oviposition or

96 larval nutrition substrate (35-37). Most melanogaster subgroup species are generalists that 
Sarikaya et al. Hawai'ian Drosophila

97 oviposit on a variety of decaying fruits, and mean ovariole number in this subgroup ranges from

9843 to 18 per female $(1,34)$. In contrast, D. erecta and D. sechellia are specialists on Pandanus

99 fruit and the toxic Morinda fruit, respectively $(38,39)$, and D. sechellia has the lowest reported

100 ovariole number of the group (1). This reduction in ovariole number has been hypothesized to be

101 the result of increased egg size as an adaptation to feeding on the toxic Morinda (40), or to be

102 due to lower insulin signaling levels evolved in response to the relatively constant nutritional

103 input provided by substrate specialization (35). Reviewing data on oviposition behavior in

104 melanogaster subgroup species, Lachaise (37) proposed that the high ovariole number observed

105 in the generalists $D$. melanogaster and $D$. simulans may be driven by the frequent oviposition

106 opportunities available to these species, as they oviposit on most decaying fruit. However, the

107 melanogaster subgroup is not well-suited for a broader understanding of ovariole number

108 evolution, as most species share similar oviposition substrates (i.e. rotting fruit) and there are few

109 independent instances of evolution of specialists.

In contrast, Hawai'ian Drosophila have evolved to specialize on a variety of oviposition

111 substrates, including decaying flowers, leaves, fungi, sap fluxes, and bark of native plants, and

112 eggs of native spiders (41). Moreover, these flies exhibit the most extreme interspecies range of

113 ovariole number reported in the genus, ranging from two to 101 per ovary (42). Hawai'ian

114 Drosophila have undergone rapid island radiation from a common ancestor in the last 25 million

115 years, leading to over 1000 extant species (43-45). The high species diversity of Hawai'ian

116 Drosophila is spread across five monophyletic species groups that share genetic, morphological

117 and ecological similarities, and rely on different oviposition substrates (44, 46-48), as follows

118 (Figure 1): Scaptomyza are small species that primarily lay eggs on leaves or flowers. Picture

119 wing (PW) species are larger species with striking pigment patterns on their wings (49). PW 
Sarikaya et al. Hawai'ian Drosophila

120 species primarily lay eggs on decaying bark or branches of native trees, though some specialize

121 on sap fluxes (41). Modified mouthpart (MM) species, which have male-specific modifications

122 on mouthparts used during mating (50), have the largest range of egg-laying substrates,

123 specializing on decaying leaves, fungi, sap or bark (51). Haleakala species are darkly pigmented

124 flies that only lay eggs on native fungi. Lastly, most antopocerus-modified tarsus-ciliated tarsus

125 (AMC) species are leaf breeders, though there are a few exceptions that have evolved bark-

126 breeding (44).

127 Ovariole number is highest in the PW species (up to 202 per female), and lowest in

128 Scaptomyza and AMC species (as few as 2 per female) (42). Dramatic differences in ovariole

129 number between species have been hypothesized to be a result of shifts between their varied

130 oviposition substrates $(42,51)$. Other studies have posited that the divergent ovariole number

131 observed in Hawai'ian Drosophila may be a result of r-K evolution (42), given the surface area

132 of decaying trees, and the predictability of this substrate in the field (36), is greater than that of

133 other oviposition substrates $(51,52)$. However, the studies supporting these hypotheses primarily

134 sampled PW species, and used phylogenies that have since been substantially improved upon in

135 more recent studies that include expanded taxon sampling and additional loci $(44,46,48,53)$.

136 To investigate the linked effects of ecology and development underlying ovariole number

137 evolution in Hawai'ian Drosophila, we conducted phylogenetic comparative analyses of life

138 history traits from 60 species, and comparative development analyses from ten species using

139 both wild-caught flies and laboratory strains. Our results identify potential mechanisms of

140 evolutionary change in ovariole number operating at three levels of biological organization. First,

141 we found that evolutionary shifts in ecological niche could predict the dramatic differences in

142 ovariole number in Hawai'ian Drosophila. Second, whether adult body size was coupled with 
Sarikaya et al. Hawai'ian Drosophila

143 ovariole number or egg volume differed between species groups with different oviposition

144 substrates, suggesting that the allometric growth relationships between these traits evolves

145 dynamically. Finally, we found that changes in ovariole number from two to 60 per individual

146 can be explained by changes in total TFC number, suggesting that ovariole number diversity

147 evolves through the same developmental mechanism, regardless of the specific ecological

148 constraints or selective pressures.

\section{Results and Discussion}

Adult reproductive traits of Hawai'ian Drosophila

We measured three major adult traits relevant to reproductive capacity (body size,

153 ovariole number and egg volume), from field-collected females, lab-reared F1 offspring of field-

154 collected females, and females from laboratory strains (Figure 1; Table S1). Species identities of

155 field-collected females were assigned based on morphological keys or DNA barcoding (Tables

$156 \mathrm{~S} 2, \mathrm{~S} 3)$. All traits ranged over an order of magnitude within Hawai' ian Drosophila: body size

157 ranged from $0.71 \mathrm{~mm}$ for $S$. devexa to $3.12 \mathrm{~mm}$ for $D$. melanocephala, ovariole number per

158 female ranged from 2 for $S$. caliginosa to 88.5 for D. melanocephala, and egg volume ranged

159 from $0.01 \mathrm{um}^{3}$ for Bunostoma spp. group (S. palmae/ S. anomala) to $0.2 \mathrm{um}^{3}$ for D. adunca,

160 highlighting the diversity of life history traits in Hawai'ian Drosophila.

Within the melanogaster subgroup species, species-specific differences in ovariole

162 number are largely heritable $(25,54,55)$. To test whether this is also the case in Hawai'ian

163 Drosophila, we compared ovariole number of wild-caught females and their lab-reared F1

164 offspring, across five species with different egg-laying substrates. We observed no significant

165 differences between the ovariole numbers of these two generations regardless of natural substrate 
Sarikaya et al. Hawai'ian Drosophila

166 (Figure S1), indicating that species-specific differences in ovariole number are also strongly

167 genetically determined in Hawai'ian Drosophila.

Larval ecology influences ovariole number evolution

A previous study based almost exclusively on picture wing species proposed that

171 evolutionary shifts in larval ecology had driven ovariole number diversification in these flies

172 (51). To test this hypothesis across the major groups of Hawai' ian Drosophila, we compared the

173 fit of evolutionary models of ovariole number that accounted for ecologically driven evolution,

174 to those that did not. Our dataset included both specialist species that oviposit on one of bark, sap

175 flux, leaf, fungus, fruit, flower or spider-eggs, as well as generalist species that oviposit on

176 multiple decaying substrates (Figure S2). We compared the fit of five models to our data, two of

177 which ((i) Brownian Motion, BM, and (ii) an Ornstein Uhlenbeck model with a shared optimum

178 for all species, OU1) do not take into account the oviposition substrate, and three of which were

179 nested ecological models based on alternative methods of substrate classification: (iii) OU2

180 assumed two states, bark breeders and all other species, to test previous suggestions that bark-

181 breeding may drive evolution of ovariole number $(51,52)$; (iv) OU3 assumed three states,

182 Scaptomyza specialists on spider eggs and flowers, bark-breeders, and species using any other

183 substrate, to test proposals that substrates influence ovariole number evolution because of their

184 differences in carrying capacity and field predictability $(36,42)$; and (v) OU8 categorized each

185 oviposition substrate separately. These five models were fit over 100 trees sampled from the

186 posterior distribution of a Bayesian phylogenetic analysis to account for phylogenetic

187 uncertainty. 
Sarikaya et al. Hawai'ian Drosophila

bark breeders and Scaptomyza specialists, was supported as the best-fit model across a majority

Table S5), consistent with earlier hypotheses $(51,52)$. In contrast, Scaptomyza species may have experienced a dramatic decrease in ovariole number as they independently specialized on spider eggs and flowers (Fig. 2B). Taken together, our results suggest that shifts in oviposition substrate may have contributed to the evolution of diverse ovariole numbers in this group, not only for picture wing flies as predicted previously (51), but across the adaptive radiation of Hawai'ian Drosophila.

In African drosophilids and tephritid Dacus flies, generalist species that oviposit on a variety of egg-laying substrates have higher fecundity than specialists $(1,22,37)$. Moreover,

204 specialist species of African and Central American Drosophila species are more fit in the

205 presence of host-specific compounds $(40,56-58)$, some of which are toxic to other species of

207 fruit (40), while D. pachea cannot be reared in laboratory conditions without supplementing 208 media with sterols from its host cactus (59). Egg-laying substrates for Hawai'ian Drosophila 209 have divergent chemical cues and fungal populations (60). Hawai'ian Drosophila often lay few 210 eggs on unsupplemented laboratory food (see Supplemental Information), but do not change 
Sarikaya et al. Hawai'ian Drosophila

211 ovariole number when reared on this food (Figure S1). We therefore speculate that specific

212 substrate components may not only allow females to distinguish between hosts for oviposition,

213 but also may contribute to species- and substrate-specific egg laying behavior in Hawai'ian

214 Drosophila.

215

216 Evolution of specialist habitats changes allometry of reproductive traits

217 The range of Hawai'ian Drosophila body sizes is greater than that of other members of

218 the genus, spanning an order of magnitude (Table S1). To determine whether changes in

219 allometric growth might underlie reproductive trait evolution, we analyzed the allometric ratio of

220 such traits using a phylogenetic least squares (PGLS) analysis and thorax volume (thorax

221 length ${ }^{3}$ ) as a proxy for body size. We found that across all Hawai'ian Drosophila, thorax volume

222 was significantly positively correlated with both ovariole number (Figure 3A; Table 2; Table S6)

223 and egg volume (Figure 3B; Table 2; Table S6).However, individual species groups show

224 differences in trends for allometric ratios of reproductive traits. In PW and MM species, body

225 size is correlated positively with ovariole number (Figure 3A1, A2), but not with egg volume

226 (Figure 3B1, B2). In contrast, AMC and Scaptomyza species have a positive correlation with

227 body size and egg volume (Figure 3B3, B4), but not ovariole number (Figure 3A3, A4). For PW,

$228 \mathrm{MM}$, and $\mathrm{AMC}$, there is a negative correlation between ovariole number and proportional egg

229 size (Table S2; Figure S3B-D), and there is a negative correlation between ovariole number and

230 egg volume in AMC and Scaptomyza (Table 2; Figure S3I-J).

231

We note that these trends are associated with differences in life history strategies between

232 groups. PW and MM group species, in which ovariole number increases with increasing body

233 size (Figure 3A1, A2), lay eggs in abundant and varied substrates (41): PW are primarily bark 
Sarikaya et al. Hawai'ian Drosophila

234 breeders that oviposit eggs in clutches of up to 100 eggs (42), and MM group species can occupy

235 a wide range of oviposition preferences, including bark, leaf, fruit, fungus, and sap flux (41). In

236 contrast, species of AMC and Scaptomyza, in which ovariole number and body size are

237 decoupled (Figure 3A3, A4), have independently evolved use of substrates with low carrying

238 capacity: AMC group species are primarily leaf breeders, reproducing on damp leaves in the

239 forest bed, while the oviposition substrates of Scaptomyza species include ephemeral substrates,

240 such as flowers, spider eggs and fresh leaves, many of which are not occupied by other

241 Hawai'ian Drosophila species groups (41). In sum, while a positive correlation between body

242 size and fecundity is commonly posited in egg-laying animals $(11,13)$, we did not find universal

243 support for this trend across Hawai'ian Drosophila. This is, however, consistent with previous

244 studies on Diptera, wherein trends toward higher fecundity or ovariole number in larger animals

245 observed within species (11) contrast with between-species differences in ovariole number that

246 do not always correlate with body size $(22,37,61)$.

247

Larval ovary somatic cell number determines ovariole number

249 We previously identified two developmental mechanisms that can alter ovariole number

250 during development: changes in TFC number per TF and change in total TFC number (29). To

251 determine whether the same developmental mechanisms that regulate ovariole number in

252 laboratory populations, also underlie the evolution of ovariole number in natural populations, we

253 measured TF and TFC numbers in the developing larval ovaries of Hawai'ian Drosophila. Our

254 analysis of 12 species representing four of the major Hawai'ian Drosophila species groups

255 showed that even over a range of ovariole numbers spanning an order of magnitude (Figure 4;

256 Table S7), larval TF number essentially corresponded to adult ovariole number (Table S8). 
Sarikaya et al. Hawai'ian Drosophila

257

258

259

260

261

262

263

264

265

266

267

268

269

270

271

272

273

274

275

276

277

278

279

Although TFC number per TF varied somewhat between species (Figure 4A; Table S7), PGLS analysis showed no correlation between TFC number per TF and total TF number (Table 3). In contrast, average total TFC number was strongly positively correlated with TF number (Table 3; Figure 4B; Table S7), suggesting that, as in laboratory populations of D. melanogaster, changes in TFC number underlie ovariole number evolution in Hawai' ian Drosophila.

The developmental mechanism underlying ovariole number evolution is particularly interesting in light of the allometric changes in Hawai' ian Drosophila species groups. There has been some debate as to whether allometry constrains or facilitates adaptive evolution (62-64). In Hawai'ian Drosophila, the allometric relationship between two important female reproductive traits, ovariole number and egg size, was coupled to body size in different groups in different ways: when ovariole number was coupled with body size, egg size was not, and vice versa (Figure 3). These trends were associated with abundant versus scarce egg-laying substrates respectively (Figure 1). While the phenotypic integration of ovariole number and egg volume appears tightly regulated across insects (65), the coupling of ovariole number to body size appears more flexible in Hawai'ian Drosophila, suggesting that in this context, heritable changes in allometry may contribute to adaptive evolution.

Ovariole number is regulated by both by intrinsic and extrinsic growth factors, including Hippo signaling, ecdysone and insulin-like peptides, all of which can also regulate body size (26, 35, 66-68). Thus, we propose that the mechanistic basis for evolutionary change of ovariole number on different substrates, may be changes in the relative influence of nutritionally regulated circulating growth factors on the one hand, and cell-autonomous growth on the other hand, on ovarian development during larval and pupal stages. For example, we speculate that on certain substrates, the larval ovary may become less sensitive to nutritionally-mediated growth 
Sarikaya et al. Hawai'ian Drosophila

280 factors by evolving lower expression levels of growth factor receptors, and relying more on

281 tissue-specific growth factors, which could include local insulin release or cell proliferation

282 pathways such as Hippo signaling.

Taken together, we found that highly divergent ovariole number, and by proxy female

284 reproductive capacity, have evolved together with changes in egg-laying substrate across

285 Hawai'ian Drosophila. Moreover, this remarkable adaptive radiation is linked to evolutionary

286 changes in a key reproductive trait that is regulated by variation in the same developmental

287 mechanisms operating in the model species D. melanogaster.

288

\section{Materials and Methods}

Hawai'ian Drosophila were collected (69) at the Koke'e State Park and Kui'a NAR on

291 Kauai, West Maui Watershed Reserve, Makawao Forest Reserve, and Waikamoi Nature Preserve

292 on Maui, and the Volcanoes National Park and Upper Waiakea Forest Reserve on Hawai'i

293 island. Field-caught flies were brought back to the lab for species identification and phenotyping

294 of adult and larval characters. Measurements of adult ovariole number, larval TF and TFC

295 number were performed as previously described (29). Mature egg size and adult body size were

296 quantified from white light micrographs of eggs and adult thoraces using ImageJ. See

297 Supplementary Information for detailed methods.

We combined sequence data for 18 genes reported in four previous studies $(44,46,48$,

299 53) from GenBank with additional newly identified mitochondrial sequences (Table S9), and

300 used the concatenated sequences to generate trees in RAxML v8.2.3 (70). Phylogenetic

301 relationships and divergence time estimates were inferred in a Bayesian framework in BEAST v. 
Sarikaya et al. Hawai'ian Drosophila

302 2.3.2 (71, 72). All phylogenetic comparative analyses and corresponding figures were computed 303 in R version 3.2.0 (73).

304 We used reported ecological information about Hawai'ian Drosophila to code oviposition 305 site (41), calculated ancestral states for each of these character codings with BEAST using the 306 rayDISC function in the R package corHMM,v.1.18 (74), mapped the most likely ecological

307 state at each node, and pruned the resulting tree to include only tips with ovariole number data.

308 The fit of different models of trait evolution was assessed on the pruned trees in OUwie v.1.48

309 (75). See Supplementary Information for detailed methods and custom scripts.

\section{Acknowledgements}

312 This work was supported by National Institutes of Health grant number 1R01 HD073499 to

313 CGE; National Science Foundation (NSF) Doctoral Dissertation Improvement Grant number

314 DEB-1209570, a post-graduate scholarship from the Natural Sciences and Engineering Research

315 Council of Canada (NSERC) and a pre-doctoral fellowship from the Fonds de recherché du

316 Québec - Santé (FRQS) to DPS; NSF Graduate Training Fellowship to SHC; and NSF

317 Postdoctoral Research Fellowship in Biology Grant number 1523880 to LPL. 
Sarikaya et al. Hawai'ian Drosophila

\section{References}

1. R'kha S, Moreteau B, Coyne JA, \& David JR (1997) Evolution of a lesser fitness trait: egg production in the specialist Drosophila sechellia. Genetical research 69:17-23.

2. McNab BK \& Ellis HI (2006) Flightless rails endemic to islands have lower energy expenditures and clutch sizes than flighted rails on islands and continents. Comp Biochem Phys A 145(3):295311.

3. Czesak ME \& Fox CW (2003) Evolutionary ecology of egg size and number in a seed beetle: Genetic trade-off differs between environments. Evolution 57(5):1121-1132.

4. Garcia-Barros E (2000) Body size, egg size, and their interspecific relationships with ecological and life history traits in butterflies (Lepidoptera : Papilionoidea, Hesperioidea). Biol. J. Linn. Soc. 70(2):251-284.

5. Martin TE, et al. (2006) Life-history and ecological correlates of geographic variation in egg and clutch mass among passerine species. Evolution 60(2):390-398.

6. Blackburn TM (1991) An Interspecific Relationship between Egg Size and Clutch Size in Birds. Auk 108(4):973-977.

7. Sinervo B \& DeNardo DF (1996) Costs of Reproduction in the Wild: Path Analysis of Natural Selection and Experimental Tests of Causation. Evolution 50(3):1299-1313.

8. Liao WB, Lu X, \& Jehle R (2014) Altitudinal variation in maternal investment and trade-offs between egg size and clutch size in the Andrew's toad. Journal of Zoology 293(2):84-91.

9. Partridge L \& Gems D (2006) Beyond the evolutionary theory of ageing, from functional genomics to evo-gero. Trends Ecol Evol 21(6):334-340.

10. Edward DA \& Chapman T (2011) Mechanisms underlying reproductive trade-offs: Costs of reproduction. Mechanisms of Life History Evolution: The Genetics and Physiology of Life History Traits and Trade-Offs:137-152.

11. Honek A (1993) Intraspecific Variation in Body Size and Fecundity in Insects - a General Relationship. OIKOS 66(3):483-492.

12. Blueweiss L, et al. (1978) Relationships between Body Size and Some Life-History Parameters. Oecologia 37(2):257-272.

13. Monroe MJ, South SH, \& Alonzo SH (2015) The evolution of fecundity is associated with female body size but not female-biased sexual size dimorphism among frogs. J. Evol. Biol. 28(10):17931803.

14. Martin TE, Martin PR, Olson CR, Heidinger BJ, \& Fontaine JJ (2000) Parental care and clutch sizes in North and South American birds. Science 287(5457):1482-1485.

15. Schaffer WM (1974) Optimal Reproductive Effort in Fluctuating Environments. Am. Nat. 108(964):783-790.

16. Meier R, Kotrba M, \& Ferrar P (1999) Ovoviviparity and viviparity in the Diptera. Biol. Rev. 74(3):199-258.

17. Stearns SC (1989) Trade-Offs in Life-History Evolution. Funct. Ecol. 3(3):259-268.

18. David JR (1970) Le nombre d'ovarioles chez Drosophila melanogaster: relation avec la fécondité et valeur adaptive. Archives de Zoologie Expérimentale et Générale 111:357-370.

19. Klepsatel P, et al. (2013) Reproductive and post-reproductive life history of wild-caught Drosophila melanogaster under laboratory conditions. J. Evol. Biol. 26(7):1508-1520.

20. King RC (1970) Ovarian Development in Drosophila melanogaster (Academic Press, New York) p 227.

21. Faille A \& Pluot-Sigwalt D (2015) Convergent Reduction of Ovariole Number Associated with Subterranean Life in Beetles. PLoS ONE 10(7):e0131986.

22. Fitt GP (1990) Comparative fecundity, clutch size, ovariole number and egg size of Dacus tyroni and D. jarvisi, and their relationship to body size. Entomologia Experimentalis et Applicata 55:11-21. 
bioRxiv preprint doi: https://doi.org/10.1101/470898; this version posted November 16,2018 . The copyright holder for this preprint (which was not certified by peer review) is the author/funder, who has granted bioRxiv a license to display the preprint in perpetuity. It is made available under aCC-BY 4.0 International license.

Sarikaya et al. Hawai'ian Drosophila

23. Wellings PW, Leather SR, \& Dixon AFG (1980) Seasonal-Variation in Reproductive Potential - a Programmed Feature of Aphid Life-Cycles. J Anim Ecol 49(3):975-985.

24. Taylor BJ \& Whitman DW (2010) A test of three hypotheses for ovariole number determination in the grasshopper Romalea microptera. Physiol Entomol 35(3):214-221.

25. Orgogozo V, Broman KW, \& Stern DL (2006) High-resolution quantitative trait locus mapping reveals sign epistasis controlling ovariole number between two Drosophila species. Genetics 173(1):197-205.

26. Sarikaya DP \& Extavour CG (2015) The Hippo pathway regulates homeostatic growth of stem cell niche precursors in the Drosophila ovary. PLoS Genetics 11(2):e1004962.

27. Branquart E \& Hemptinne JL (2000) Development of ovaries, allometry of reproductive traits and fecundity of Episyrphus balteatus (Diptera : Syrphidae). Eur J Entomol 97(2):165-170.

28. Grenier AM \& Nardon P (1994) The Genetic-Control of Ovariole Number in Sitophilus-Oryzae L (Coleoptera, Curculionidae) Is Temperature-Sensitive. Genet. Sel. Evol. 26(5):413-430.

29. Sarikaya DP, et al. (2012) The roles of cell size and cell number in determining ovariole number in Drosophila. Dev. Biol. 363:279-289

30. Sahut-Barnola I, Godt D, Laski FA, \& Couderc J-L (1995) Drosophila Ovary Morphogenesis: Analysis of Terminal Filament Formation and Identification of a Gene Required for This Process. Dev. Biol. 170(1):127-135.

31. Godt D \& Laski FA (1995) Mechanisms of cell rearrangement and cell recruitment in Drosophila ovary morphogenesis and the requirement of bric à brac. Development 121:173-187.

32. Green II DA, Sarikaya DP, \& Extavour CG (2011) Counting in oogenesis. Cell Tissue Res. 344(2):207-212.

33. Hodin J \& Riddiford LM (1998) The ecdysone receptor and ultraspiracle regulate the timing and progression of ovarian morphogenesis during Drosophila metamorphosis. Dev. Genes Evol. 208(6):304-317.

34. Markow TA \& O'Grady PM (2007) Drosophila biology in the genomic age. Genetics 177(3):1269-1276.

35. Green II DA \& Extavour CG (2014) Insulin Signaling Underlies Both Plasticity and Divergence of a Reproductive Trait in Drosophila. Proc. R. Soc. Lond. B. Biol. Sci. 281(1779):20132673.

36. Montague JR, Mangan RL, \& Starmer WT (1981) Reproductive Allocation in the Hawaiian Drosophilidae - Egg Size and Number. American Naturalist 118(6):865-871.

37. Lachaise D (1983) Reproductive Allocation in Tropical Drosophilidae - Further Evidence on the Role of Breeding-Site Choice. Am. Nat. 122(1):132-146.

38. Tsacas L \& Bächli G (1981) Drosophila sechellia, n.sp., huitieme espece du sous-goupe melanogaster des Iles Sechelles [Diptera, Drosophilidae]. Revue Francaise d'Entomologie 3(4):146-150.

39. Rio B, Couturier G, Lemeunier F, \& Lachaise D (1983) Evolution d'une specialisation saisonniere chez Drosophila erecta (Dipt., Drosophilidae). Annales de la Société Entomologique de France 19:235-248.

40. Lavista-Llanos S, et al. (2014) Dopamine drives Drosophila sechellia adaptation to its toxic host. eLife $3: \mathrm{e} 03785$.

41. Magnacca K, Foote D, \& O'Grady PM (2008) A review of the endemic Hawaiian Drosophilidae and their host plants. Zootaxa 1728:1-58.

42. Kambysellis MP \& Heed WB (1971) Studies of Oogenesis in Natural Populations of Drosophilidae. I. Relation of ovarian development and ecological habitats of the hawaiian species. Am. Nat. 941(105):31-49.

43. O'Grady P \& DeSalle R (2018) Hawaiian Drosophila as an Evolutionary Model Clade: Days of Future Past. BioEssays 40(5):e1700246.

44. O'Grady PM, et al. (2011) Phylogenetic and ecological relationships of the Hawaiian Drosophila inferred by mitochondrial DNA analysis. Mol Phylogenet Evol 58(2):244-256. 
Sarikaya et al. Hawai'ian Drosophila

45. Tamura K, Subramanian S, \& Kumar S (2004) Temporal patterns of fruit fly (Drosophila) evolution revealed by mutation clocks. Mol. Biol. Evol. 21(1):36-44.

46. Lapoint RT, O'Grady PM, \& Whiteman NK (2013) Diversification and dispersal of the Hawaiian Drosophilidae: the evolution of Scaptomyza. Mol Phylogenet Evol 69(1):95-108.

47. Lapoint RT, Gidaya A, \& O'Grady PM (2011) Phylogenetic relationships in the spoon tarsus subgroup of Hawaiian Drosophila: conflict and concordance between gene trees. Mol Phylogenet Evol 58(3):492-501.

48. Magnacca KN \& Price DK (2015) Rapid adaptive radiation and host plant conservation in the Hawaiian picture wing Drosophila (Diptera: Drosophilidae). Mol. Phylogenet. Evol. 92:226-242.

49. Edwards KA, Doescher LT, Kaneshiro KY, \& Yamamoto D (2007) A database of wing diversity in the Hawaiian Drosophila. PLoS ONE 2(5):e487.

50. Magnacca KN \& O'Grady PM (2006) A Subgroup Structure for the Modified Mouthparts Species Group of Hawaiian Drosophila. Proceedings Of The Hawaiian Entomological Society 38:87-101.

51. Kambysellis MP, et al. (1995) Pattern of ecological shifts in the diversification of Hawaiian Drosophila inferred from a molecular phylogeny. Curr. Biol. 5(10):1129-1139.

52. Craddock EM \& Kambysellis MP (1997) Adaptive Radiation in the Hawaiian Drosophila (Diptera: Drosophilidae): Ecological and Reproductive Character Analyses. Pacific Science 51(4):475-489.

53. Lapoint RT, Magnacca KM, \& O'Grady PM (2014) Phylogenetics of the Antopocerus-Modified Tarsus Clade of Hawaiian Drosophila: Diversification across the Hawaiian Islands. PLoS ONE 9(11):e113227.

54. Wayne ML, et al. (2001) Quantitative trait locus mapping of fitness-related traits in Drosophila melanogaster. Genetical research 77(1):107-116.

55. Bergland AO, Genissel A, Nuzhdin SV, \& Tatar M (2008) Quantitative trait loci affecting phenotypic plasticity and the allometric relationship of ovariole number and thorax length in Drosophila melanogaster. Genetics 180(1):567-582.

56. Peluso D, Soto EM, Kreiman L, Hasson E, \& Mensch J (2016) Contrasting Plasticity in Ovariole Number Induced by A Dietary Effect of the Host Plants between Cactophilic Drosophila Species. Insects 7(2).

57. Lang M, et al. (2012) Mutations in the neverland Gene Turned Drosophila pachea into an Obligate Specialist Species. Science 337(6102):1658-1661.

58. Matzkin LM, Johnson S, Paight C, Bozinovic G, \& Markow TA (2011) Dietary Protein and Sugar Differentially Affect Development and Metabolic Pools in Ecologically Diverse Drosophila. J. Nutr. 141(6):1127-1133.

59. Heed WB \& Kircher HW (1965) Unique Sterol in Ecology and Nutrition of Drosophila Pachea. Science 149(3685):758-\&.

60. Ort BS, Bantay RM, Pantoja NA, \& O\&apos;Grady PM (2012) Fungal Diversity Associated with Hawaiian Drosophila Host Plants. PLoS ONE 7(7):e40550.

61. Soto IM, et al. (2014) Differences in tolerance to host cactus alkaloids in Drosophila koepferae and D. buzzatii. PLoS ONE 9(2):e88370.

62. Smith JM, et al. (1985) Developmental Constraints and Evolution. Q. Rev. Biol. 60(3):265-287.

63. Lande R (1985) Genetic and Evolutionary Aspects of Allometry. Size and Scaling in Primate Biolgy, Advances in Primatology, ed Jungers WJ (Plenum Press, New York), pp 21-32.

64. Bonduriansky R (2007) Sexual selection and allometry: a critical reappraisal of the evidence and ideas. Evolution 61(4):838-849.

65. Berrigan D (1991) The allometry of egg size and number in insects. OIKOS 60:313-321.

66. Hodin J \& Riddiford LM (2000) Parallel alterations in the timing of ovarian ecdysone receptor and ultraspiracle expression characterize the independent evolution of larval reproduction in two species of gall midges (Diptera: Cecidomyiidae). Dev. Genes Evol. 210(7):358-372. 
Sarikaya et al. Hawai'ian Drosophila

67. Gancz D, Lengil T, \& Gilboa L (2011) Coordinated regulation of niche and stem cell precursors by hormonal signaling. PLoS Biol. 9(11):e1001202.

68. Gancz D \& Gilboa L (2013) Insulin and Target of rapamycin signaling orchestrate the development of ovarian niche-stem cell units in Drosophila. Development 140(20):4145-4154.

69. Markow TA \& O'Grady PM (2006) Chapter 4 - Collecting Drosophila in the wild. Drosophila: $A$ Guide to Species Identificaton and Use, (Academic Press), pp 145-153.

70. Stamatakis A (2006) RAxML-VI-HPC: maximum likelihood-based phylogenetic analyses with thousands of taxa and mixed models. Bioinformatics 22(21):2688-2690.

71. Bouckaert R, et al. (2014) BEAST 2: A Software Platform for Bayesian Evolutionary Analysis. Plos Computational Biology 10(4).

72. Drummond AJ \& Rambaut A (2007) BEAST: Bayesian evolutionary analysis by sampling trees. BMC Evol. Biol. 7.

73. Team RC (2015) R: A language and environment for statistical computing. R Foundation for Statistical Computing, Vienna, Austria.

74. Beaulieu JM, Oliver JC, \& O'Meara B (2012) corHMM: Hidden Markov Models in R, Version 1.0 .

75. Beaulieu JM \& O'Meara B (2014) OUwie: Analysis of Evolutionary Rates in an OU Framework. $R$ package version 1 .

76. Pinheiro J, Bates D, DebRoy S, Sarkar D, \& Team RC (2014) Nlme: Linear and Nonlinear Mixed Effects Models. $R$ Package Version 3.1-117 https://CRAN.R-project.org/package=nlme. 


\section{Figure Legends}

Figure 1. Reproductive and ecological traits of Hawai'ian Drosophila in phylogenetic

492 context. Compiled adult life history traits (greyscale gradients) collected herein and by

493 Kambysellis and Heed (42) are mapped on a phylogeny of Hawai'ian Drosophila constructed

494 from available mitochondrial and nuclear genes. Egg-laying substrate of each species is indicated 495 by colored boxes: bark (brown), generalist (black), sap flux (yellow), leaf (green), fungus

496 (purple), fruit (red), spider eggs (blue), flowers (pink), and unknown (gray). Boxes with solid

497 outlines denote data collected in the present study; boxes with four notches denote data

498 represented in our data and those of Kambysellis and Heed (42); boxes with dotted outline

499 denote data represented only in Kambysellis and Heed (42). Missing boxes indicate data points

500 that were either not previously reported (42) or that we were unable to obtain from field-caught

501 samples. Black lines at right delineate the five major groups of Hawai'ian Drosophila as follows:

$502 \mathrm{SCAP}=$ Scaptomyza $; \mathrm{PW}=$ picture wing $; \mathrm{MM}=$ modified mouthparts $; \mathrm{H}=$ Haleakala $;$ AMC $=$ 503 antopocerus-modified tarsus-ciliated tarsus.

Figure 2. Different ecological states tested for OU analysis. (A) A two-state model (OU2) of

506 bark-breeders (brown) and non-bark breeders (white). (B) Three-state model (OU3) that codes

507 bark-breeders (brown), spider egg and flower breeders (blue), and other oviposition substrates

508 (white). (C) Eight-state model (OU8) that codes each egg-laying substrate separately, color

509 coded as in Figure 1. Pie charts show the maximum likelihood ancestral state estimates at each

510 node, calculated with the rayDISC function in the R package corHMM,v.1.18 (74). 
Sarikaya et al. Hawai'ian Drosophila

512 Figure 3. Allometric relationship between life history traits in Hawai'ian Drosophila.

513 Scatter plots of log transformed adult measurements with phylogenetically transformed trend

514 lines generated by averaging runs from PGLS analysis across 100 posterior distribution BEAST

515 trees, performed with the R package nlme v.3.1-121 (76). Trend line of the consensus tree is

516 denoted in red when there was a significant relationship between the two traits, and black when

517 PGLS analysis did not support a significant relationship (Table 2). (A, A1-A4) Ovariole number 518 plotted against thorax volume $\left(\mathrm{mm}^{3}\right)$ in (A) all specimens, (A1) PW, (A2) MM, (A3) AMC, and

519 (A4) Scaptomyza. (B, B1-B4) Egg volume $\left(\mu \mathrm{m}^{3}\right)$ plotted against thorax volume $\left(\mathrm{mm}^{3}\right)$ in $(\mathrm{B})$ all 520 specimens, (B1) PW, (B2) MM, (B3) AMC, and (B4) Scaptomyza.

Figure 4. Terminal filament cell (TFC) number predicts terminal filament (TF) number in

523 Hawai' ian Drosophilids. (A-C) Bar graphs for (A) TFC number per TF, (B) total TFC number,

524 and (C) TF number per larval ovary representing the mean and standard deviation, as well as the

525 phylogenetic relationship between the species shown (bottom). (D-F) Late third instar larval

526 ovaries stained for nuclei (purple) and F-actin (green) for (D) S. caliginosa (flower breeder), (E)

527 D. silvestris (bark breeder), (G) D. mitchelli (egg-laying substrate unknown), and (F) D.

528 tanythrix (leaf breeder). Numbers in parentheses beside species names indicate mean ovariole

529 number per ovary (Tables S7, S8). White arrowheads indicate TF structures in the ovary. 
bioRxiv preprint doi: https://doi.org/10.1101/470898; this version posted November 16, 2018. The copyright holder for this preprint (which was not certified by peer review) is the author/funder, who has granted bioRxiv a license to display the preprint in perpetuity. It is made available under aCC-BY 4.0 International license.

Sarikaya et al. Hawai'ian Drosophila

\section{Figure 1}

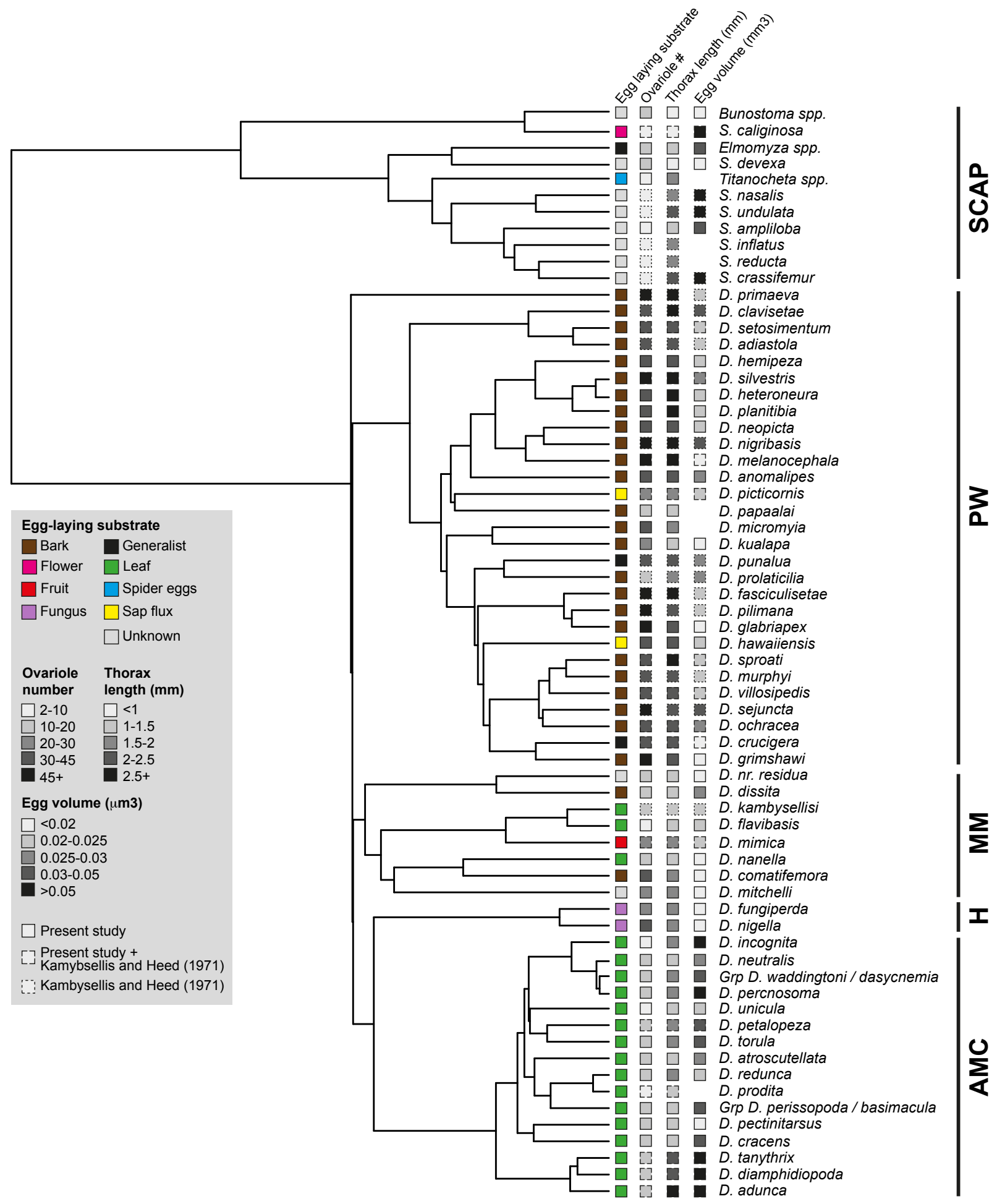


534

(A) Two state (OU2)

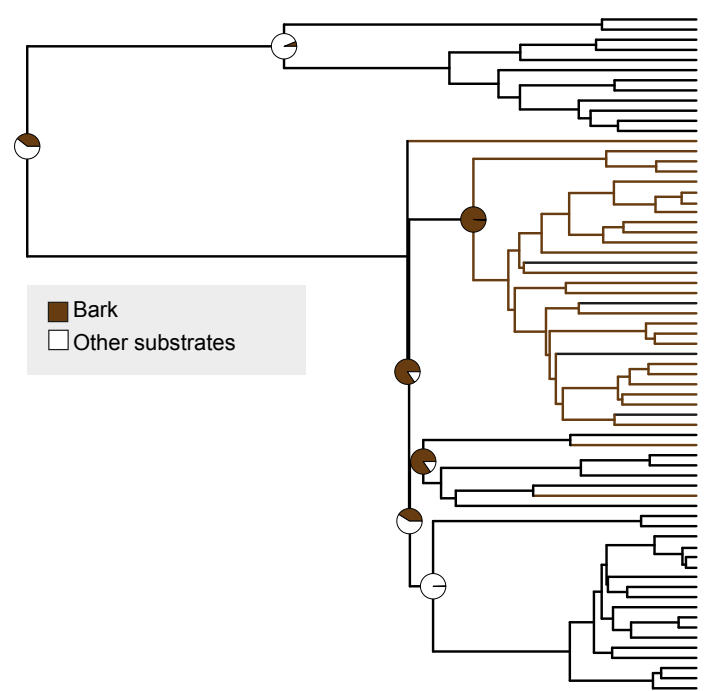

(B) Three state (OU3)

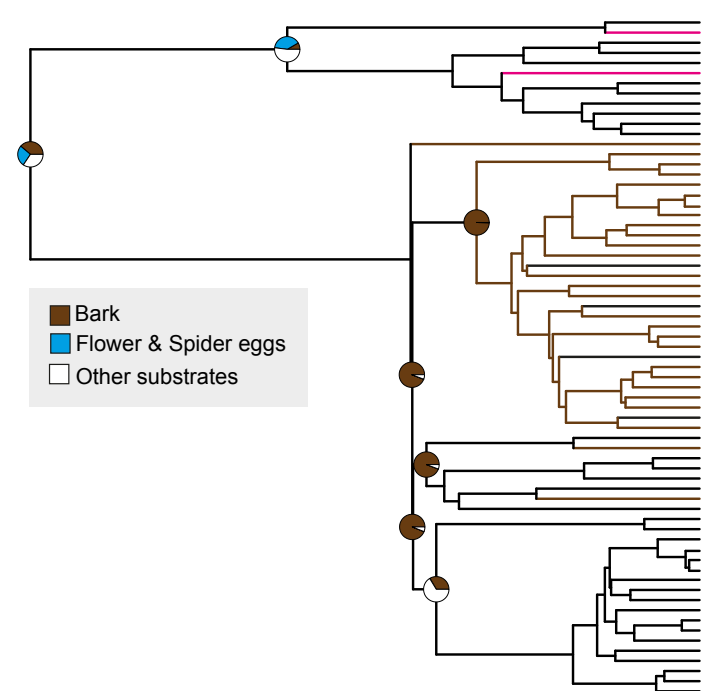

(C) Eight state (OU8)

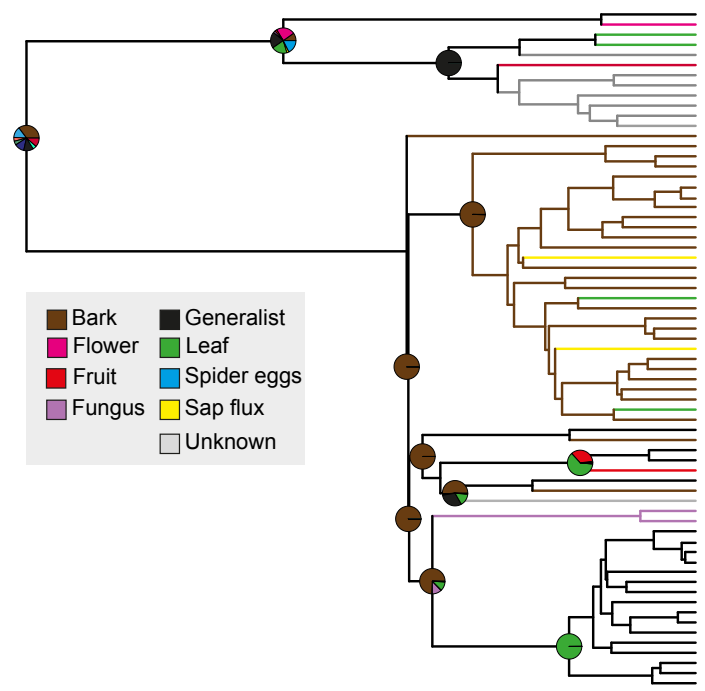


bioRxiv preprint doi: https://doi.org/10.1101/470898; this version posted November 16,2018 . The copyright holder for this preprint (which was not certified by peer review) is the author/funder, who has granted bioRxiv a license to display the preprint in perpetuity. It is made available under aCC-BY 4.0 International license.

Sarikaya et al. Hawai'ian Drosophila

Figure 3

\section{OPW OMM OAMC $\bigcirc$ Scaptomyza $\bigcirc$ Haleakala}
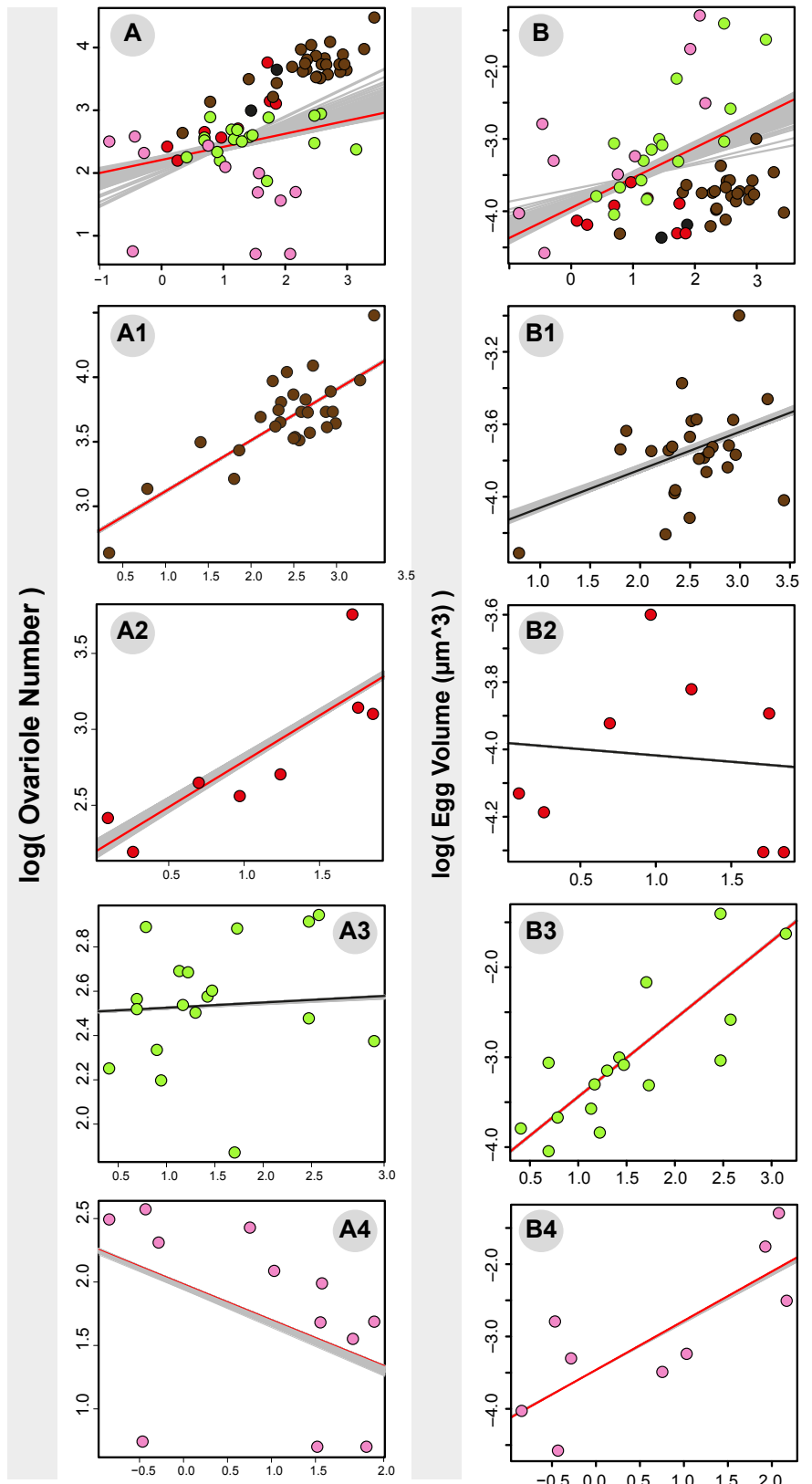

$\log \left(\right.$ Thorax Volume $\left.\left(\mathrm{mm}^{\wedge} \mathbf{3}\right)\right)$

$\log$ (Thorax Volume $\left(\mathrm{mm}^{\wedge} \mathbf{3}\right)$ ) 

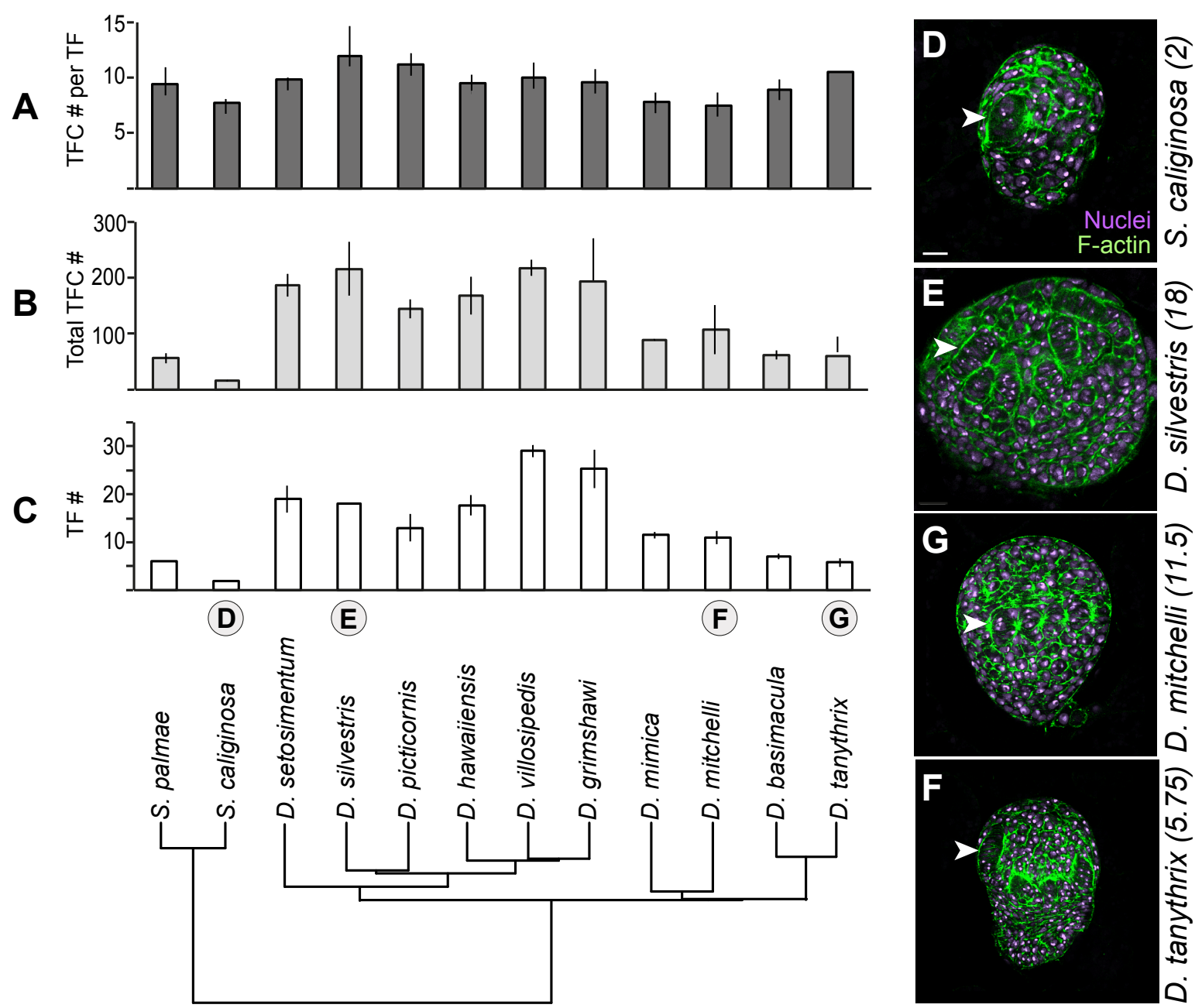
Sarikaya et al. Hawai'ian Drosophila

541 Table 1. Comparison of AICc and weighted AICc values for models testing the relationship 542 between oviposition substrate and ovariole number. Values are for model fit of Brownian 543 motion (BM) and Ornstein-Uhlenbeck with one optimum (OU1) or with multiple optima (OUM) 544 with different combinations of oviposition substrate categories, calculated with the R package 545 OUwie v.1.48 (75). Oviposition substrates were categorized as follows: OU2 categorizes species 546 that lay eggs on bark and non-bark; OU3 categorizes species into bark-breeder, spider egg/flower 547 breeder, and other; and OU8 categorizes each species according to the eight oviposition 548 substrates represented (bark, flower, spider egg, fruit, leaf, generalist, fungus, sap flux). Models 549 were tested over 1000 posterior distribution BEAST trees using nuclear and mitochondrial gene 550 sequences. Bold indicates the best supported model.

\begin{tabular}{|l|r|r|r|}
\hline & AICc & \multicolumn{2}{r|}{ AICc $w(A I C)$} \\
\hline BM & 86.26 & 5.91 & 0.04 \\
\hline OU1 & 88.41 & 8.06 & 0.01 \\
\hline OU2 & 84.84 & 4.49 & 0.1 \\
\hline OU3 & $\mathbf{8 0 . 3 5}$ & $\mathbf{0}$ & $\mathbf{0 . 7 7}$ \\
\hline OU8 & 84.42 & 4.07 & 0.08 \\
\hline
\end{tabular}


Table 2. Phylogenetic Generalized Least Squares (PGLS) analysis of adult reproductive traits in Hawai'ian Drosophila. PGLS analysis of relationships between ovariole number and thorax volume $\left(\mathrm{mm}^{3}\right)$, egg volume $\left(\mu \mathrm{m}^{3}\right)$ and thorax volume, and ovariole number and proportional egg volume $\left(\mu \mathrm{m}^{3} / \mathrm{mm}^{3}\right)$ are listed. Regression analyses were performed with the R package nIme v.3.1-121 (76) on 100 trees from a BEAST posterior distribution using nuclear and mitochondrial genes, and the minimum, average, and maximum slope and p-value for the analysis is included in the table. P-values below 0.01 are indicated in bold.

\begin{tabular}{|c|c|c|c|c|c|c|c|c|c|c|c|c|c|c|c|c|}
\hline & & \multicolumn{3}{|c|}{ All species groups } & \multicolumn{3}{|c|}{ PW spp. } & \multicolumn{3}{|c|}{ AMC spp. } & \multicolumn{3}{|c|}{ MM spp. } & \multicolumn{3}{|c|}{ Scaptomyza spp. } \\
\hline & & $\min$ & avg & $\max$ & $\min$ & avg & $\max$ & $\min$ & avg & $\max$ & $\min$ & avg & $\max$ & $\min$ & avg & $\max$ \\
\hline \multirow[t]{2}{*}{$\begin{array}{l}\text { ON - Thorax volume } \\
(\mathrm{mm} 3)\end{array}$} & Slope & 0.234 & 0.292 & 0.500 & 0.412 & 0.416 & 0.424 & 0.014 & 0.019 & 0.020 & 0.572 & 0.598 & 0.627 & 0.307 & 0.284 & $0.276^{-}$ \\
\hline & $\begin{array}{l}p- \\
\text { value }\end{array}$ & 0.000 & 0.002 & 0.011 & 0.000 & 0.000 & 0.000 & 0.841 & 0.845 & 0.892 & 0.001 & 0.004 & 0.008 & 0.134 & 0.150 & 0.174 \\
\hline \multirow[t]{2}{*}{$\begin{array}{l}\text { Egg volume }(\mu \mathrm{m} 3) \text { - } \\
\text { Thorax volume } \\
(\mathrm{mm} 3)\end{array}$} & Slope & 0.156 & 0.353 & 0.407 & 0.164 & 0.185 & 0.164 & 0.745 & 0.748 & 0.760 & 0.038 & 0.038 & 0.037 & 0.654 & 0.679 & 0.680 \\
\hline & $\begin{array}{l}p- \\
\text { value }\end{array}$ & 0.000 & 0.000 & 0.058 & 0.086 & 0.109 & 0.164 & 0.000 & 0.000 & 0.000 & 0.811 & 0.811 & 0.811 & 0.012 & 0.012 & 0.016 \\
\hline \multirow[t]{2}{*}{$\begin{array}{l}\text { ON - Proportional } \\
\text { Egg volume } \\
(\mu \mathrm{m} 3 / \mathrm{mm} 3)\end{array}$} & Slope & $0.649^{-}$ & $0.570^{-}$ & $0.532^{-}$ & 0.453 & 0.445 & 0.438 & 0.321 & -0.321 & $0.314^{-}$ & 0.686 & 0.659 & 0.648 & $0.570^{-}$ & $0.473^{-}$ & 0.367 \\
\hline & $\begin{array}{l}\mathrm{p}- \\
\text { value }\end{array}$ & 0.000 & 0.000 & 0.000 & 0.000 & 0.000 & 0.000 & 0.007 & 0.008 & 0.010 & 0.000 & 0.001 & 0.001 & 0.084 & 0.170 & 0.306 \\
\hline \multirow[t]{2}{*}{$\begin{array}{l}\text { ON - Egg volume } \\
(\mu \mathrm{m} 3)\end{array}$} & Slope & 0.703 & -0.42 & 0.376 & 0.088 & 0.081 & -0.07 & 0.308 & 0.2224 & 0.161 & 0.689 & 0.689 & 0.689 & $0.784^{-}$ & 0.676 & 0.567 \\
\hline & $\begin{array}{l}\mathrm{p}- \\
\text { value }\end{array}$ & 0.000 & 0.000 & 0.000 & 0.674 & 0.695 & 0.739 & 0.008 & 0.049 & 0.127 & 0.396 & 0.396 & 0.397 & 0.001 & 0.003 & 0.007 \\
\hline
\end{tabular}


bioRxiv preprint doi: https://doi.org/10.1101/470898; this version posted November 16,2018 . The copyright holder for this preprint (which was not certified by peer review) is the author/funder, who has granted bioRxiv a license to display the preprint in perpetuity. It is made available under aCC-BY 4.0 International license.

Sarikaya et al. Hawai'ian Drosophila

562 Table 3. Phylogenetic Generalized Least Squares (PGLS) analysis of larval ovarian

563 measurements in Hawai'ian Drosophila. Relationships between TF number and TFC number 564 per TF, TF number and total TFC number, and total TFC number and TFC number per TF are 565 listed. Regression analyses were performed with the R package nlme v.3.1-121 (76) on 100 trees 566 from a BEAST posterior distribution using nuclear and mitochondrial genes, and the minimum, 567 average, and maximum slope and p-value for the analysis is included in the table. P-values below $568 \quad 0.01$ are indicated in bold.

569

\begin{tabular}{|l|l|c|c|c|}
\hline \multicolumn{1}{|l|}{} & & $\min$ & avg & $\max$ \\
\hline TF \# - TFC \# per TF & Slope & 0.320 & 0.744 & 1.728 \\
& p-value & 0.199 & 0.376 & 0.647 \\
\hline TF \# - Total TFC \# & Slope & 0.873 & 0.873 & 0.873 \\
& p-value & $\mathbf{0 . 0 0 0}$ & $\mathbf{0 . 0 0 0}$ & $\mathbf{0 . 0 0 0}$ \\
\hline TFC \# per TF - Total TFC \# & Slope & 0.097 & 0.097 & 0.097 \\
& p-value & 0.059 & 0.059 & 0.059 \\
\hline
\end{tabular}

